\title{
Evaluation and analysis of uncertainty of wet expansion measurement of ceramic brick
}

\author{
Chen Weizhe ${ }^{1}$ \\ ${ }^{1}$ Quality and Technical Supervision and Inspection Center of Xuchang (National Quality Supervision and Inspection Center for Ceramic \\ Products of China (Henan)),Xuchang, Henan China
}

\begin{abstract}
With the continuous and high-speed growth of economy, people's requirements on product quality are increasing year by year, including ceramic brick products, which, as a typical building materials product, are widely used in all kinds of buildings of different sizes.Quality of brick of pottery and porcelain products mainly in the form of through the examination and evaluation, the uncertainty of measurement as an important part of the test results, is an important parameter characterization of the reliability of the measurement result, therefore, this article analyzes the brick of pottery and porcelain wet expand sources of uncertainty in measurement, using the measurement results and related data, the uncertainty of the measurement result was evaluated.
\end{abstract}

\section{Introduction}

At present, China has developed into the world's largest manufacturer of building and sanitary ceramics. According to statistics, from January to December 2019, the main business income of the building ceramic industry above designated size was 307.99 billion yuan, and the national ceramic tile output was 10.161 billion square meters. Quantitative changes cause qualitative changes, and qualitative changes are inseparable from the improvement of detection technology, and measurement uncertainty is an important indicator that reflects the level of detection technology. JJF1059.1-2012 "Measuring Uncertainty and Expression" clearly stated that the final form of measurement results should be evaluated and expressed by uncertainty. The uncertainty of measurement results is becoming more and more common. Research on the evaluation of uncertainty of measurement results The results are endless, involving all aspects [1]-[3]. Therefore, this article takes the typical building material product - ceramic tile product as the research object to carry out the evaluation and analysis of the uncertainty of ceramic tile wet expansion measurement.

\section{Measurement and analysis of wet expansion of ceramic tiles}

According to GB/T3810.10-2016 standard to measure the wet expansion of ceramic tiles.

\subsection{Measuring principle and equipment}

The measuring principle is to accelerate the occurrence of wet expansion by immersing the brick in boiling water and heating it, and measure the length change ratio; measuring instruments and equipment include roasting furnace, vernier caliper, etc.

\subsection{Measurement method}

\subsubsection{Reburn}

Put the sample into the roasting furnace, re-fire at a heating rate of $150^{\circ} \mathrm{C} / \mathrm{h}$, raise it to $(550 \pm 15)^{\circ} \mathrm{C}$, keep it at $(550 \pm 15)^{\circ} \mathrm{C}$ for $2 \mathrm{~h}$, let the sample cool in the furnace, when the temperature drops to (At $70 \pm 10)^{\circ} \mathrm{C}$, put the sample in a desiccator and keep it at room temperature $(24 \sim 32) \mathrm{h}$. If the sample cracks after reburning, take another sample and reheat it at a slower rate of heating and cooling. Roasting. Measure the initial length of each sample relative to the nickel steel standard block to the nearest $0.5 \mathrm{~mm}$, and measure the sample again after $3 \mathrm{~h}$.

\subsubsection{Boiling water treatment}

Heat the container with deionized water or distilled water to boiling, and immerse the sample in boiling water. Keep the water level at least $5 \mathrm{~cm}$ higher than the sample, so that the samples do not touch each other, and do not touch the bottom and walls of the container. Boil for $24 \mathrm{~h}$. Take out the sample from the boiling water and cool it to 
room temperature, measure the length of the sample after $1 \mathrm{~h}$, measure it again after 3 , and record the measurement result. For each sample, calculate the average of the two measurements before boiling water treatment and the average of the two measurements after boiling water treatment, and then calculate the difference between the two averages.

\subsubsection{Results presentation}

When the wet expansion is expressed in $\mathrm{mm} /$ per meter, it is calculated by the following formula:

$$
\frac{\Delta L}{L} \times 100
$$

Where:

$\Delta \mathrm{L}$ - is the difference between the two average values before and after boiling water treatment, in millimeters ( $\mathrm{mm})$;

$\mathrm{L}$ - is the average initial length of the sample, in millimeters (mm).

\section{Measurement uncertainty analysis}

\subsection{The main sources and analysis of uncertainty}

The main sources of uncertainty introduced in the measurement process are:

The random factors that affect the test results mainly include the variability of the measurement environment, the difference in personnel operations, the uncertainty of the roaster and the boiling device, etc.

\subsection{Mathematical model}

It is difficult to quantitatively study the influence of each influencing factor in actual evaluation. A simpler and easier method is to measure multiple samples of the same batch under repeatability measurement conditions, and calculate the standard deviation of the observation column, which is used as various random factors to synthesize the repeatability uncertainty component. Usually, the measurement result is multiplied by the repeatability factor frep, which is equal to 1 , and its standard deviation is equal to the relative combined standard uncertainty of the measurement result. Therefore, the mathematical model for evaluating uncertainty should be written as:

$$
X=X_{i} \times f_{\text {rep }}
$$

\subsection{Evaluation of the uncertainty component introduced by measurement repeatability}

In this measurement, 10 test samples were measured in parallel, and the measurement results obtained are shown in Table 1.

\begin{tabular}{|c|c|c|c|c|c|c|c|c|c|c|}
\hline Number & 1 & 2 & 3 & 4 & 5 & 6 & 7 & 8 & 9 & 10 \\
\hline$L_{1}$ & $\begin{array}{l}100 . \\
462\end{array}$ & $\begin{array}{l}100 . \\
927\end{array}$ & $\begin{array}{l}100 . \\
552\end{array}$ & $\begin{array}{l}100 . \\
920\end{array}$ & $\begin{array}{l}100 . \\
723\end{array}$ & $\begin{array}{l}100 . \\
578\end{array}$ & $\begin{array}{l}100 . \\
598\end{array}$ & $\begin{array}{l}100 . \\
844\end{array}$ & $\begin{array}{l}100 . \\
806\end{array}$ & $\begin{array}{l}100 . \\
752\end{array}$ \\
\hline$L_{2}$ & $\begin{array}{l}100 . \\
462\end{array}$ & $\begin{array}{l}100 . \\
927\end{array}$ & $\begin{array}{l}100 . \\
552\end{array}$ & $\begin{array}{l}100 . \\
920\end{array}$ & $\begin{array}{l}100 \\
723\end{array}$ & $\begin{array}{l}100 . \\
578\end{array}$ & $\begin{array}{l}100 . \\
598\end{array}$ & $\begin{array}{l}100 . \\
844\end{array}$ & $\begin{array}{l}100 . \\
806\end{array}$ & $\begin{array}{l}100 \\
752\end{array}$ \\
\hline$L_{01}=\left(L_{1}+L_{2}\right) / 2$ & $\begin{array}{l}100 . \\
462 \\
\end{array}$ & $\begin{array}{l}100 . \\
927\end{array}$ & $\begin{array}{l}100 . \\
552 \\
\end{array}$ & $\begin{array}{l}100 . \\
920\end{array}$ & $\begin{array}{l}100 . \\
723\end{array}$ & $\begin{array}{l}100 . \\
578\end{array}$ & $\begin{array}{l}100 . \\
598 \\
\end{array}$ & $\begin{array}{l}100 . \\
844\end{array}$ & $\begin{array}{l}100 . \\
806\end{array}$ & $\begin{array}{l}100 . \\
752 \\
\end{array}$ \\
\hline$L_{3}$ & $\begin{array}{l}100 . \\
465\end{array}$ & $\begin{array}{l}100 . \\
930\end{array}$ & $\begin{array}{l}100 . \\
554\end{array}$ & $\begin{array}{l}100 . \\
923\end{array}$ & $\begin{array}{l}100 . \\
726\end{array}$ & $\begin{array}{l}100 . \\
580\end{array}$ & $\begin{array}{l}100 . \\
602\end{array}$ & $\begin{array}{l}100 . \\
847\end{array}$ & $\begin{array}{l}100 . \\
808\end{array}$ & $\begin{array}{l}100 . \\
755\end{array}$ \\
\hline$L_{4}$ & $\begin{array}{l}100 . \\
465\end{array}$ & $\begin{array}{l}100 . \\
930\end{array}$ & $\begin{array}{l}100 . \\
554\end{array}$ & $\begin{array}{l}100 . \\
923\end{array}$ & $\begin{array}{l}100 . \\
726\end{array}$ & $\begin{array}{l}100 \\
580\end{array}$ & $\begin{array}{l}100 . \\
602\end{array}$ & $\begin{array}{l}100 . \\
847\end{array}$ & $\begin{array}{l}100 . \\
808\end{array}$ & $\begin{array}{l}100 . \\
755\end{array}$ \\
\hline$L_{02}=\left(L_{3}+L_{4}\right) / 2$ & $\begin{array}{l}100 . \\
465\end{array}$ & $\begin{array}{l}100 . \\
930\end{array}$ & $\begin{array}{l}100 . \\
554\end{array}$ & $\begin{array}{l}100 . \\
923\end{array}$ & $\begin{array}{l}100 . \\
726\end{array}$ & $\begin{array}{l}100 \\
580\end{array}$ & $\begin{array}{l}100 . \\
602 \\
\end{array}$ & $\begin{array}{l}100 . \\
847\end{array}$ & $\begin{array}{l}100 . \\
808\end{array}$ & $\begin{array}{l}100 . \\
755\end{array}$ \\
\hline$L_{02}-L_{01} / L_{01}(\%)$ & $\begin{array}{r}0.00 \\
3\end{array}$ & $\begin{array}{c}0.00 \\
3\end{array}$ & $\begin{array}{r}0.00 \\
2\end{array}$ & $\begin{array}{r}0.00 \\
2\end{array}$ & $\begin{array}{r}0.00 \\
3\end{array}$ & $\begin{array}{r}0.00 \\
2\end{array}$ & $\begin{array}{c}0.00 \\
4\end{array}$ & $\begin{array}{c}0.00 \\
3\end{array}$ & $\begin{array}{r}0.00 \\
2\end{array}$ & $\begin{array}{c}0.00 \\
3\end{array}$ \\
\hline Average value & & & & & & & & & & \\
\hline
\end{tabular}

Table 1 Test sample measured value

The repeatability of the measurement is expressed in standard deviation and calculated according to the Bessel formula:

$$
s(X)=\sqrt{\frac{\sum_{i=1}^{n}\left(X_{i}-\bar{X}\right)^{2}}{n-1}}=7.45 \times 10^{-4}
$$

As usually 5 samples are measured at a time, the average value is used to report the result, and the 
standard deviation of the average value should be calculated as follows:

$$
s\left(\overline{X_{i}}\right)=u\left(\overline{X_{i}}\right)=\frac{7.45 \times 10^{-4}}{\sqrt{5}}=3.33 \times 10^{-4}
$$

The uncertainty of the measured repeatability factor $f_{\text {rep }}$ is:

$$
u\left(f_{\text {rep }}\right)=\frac{s\left(\overline{X_{i}}\right)}{\overline{X_{i}}}=\frac{3.33 \times 10^{-4}}{0.003}=0.111
$$

\subsection{Uncertainty introduced by vernier caliper calibration}

The expanded uncertainty reported by the vernier caliper calibration certificate is 5um, and the confidence probability is $95 \%$. The relative standard uncertainty of the measurement introduced thereby should be:

$$
u_{\text {rel }}\left(d_{\text {cali }}\right)=\frac{0.005}{1.96}=0.003
$$

\subsection{Uncertainty of composite standard}

$$
u_{c}(X)=X \times \sqrt{u^{2}\left(f_{\text {rep }}\right)+u^{2}\left(d_{\text {cali }}\right)}=3.33 \times 10^{-4}
$$

\subsection{Expanded uncertainty}

Take the inclusion factor $\mathrm{k}=2$, then expand the uncertainty

$$
U(X)=k \times u_{c}(X)=6.66 \times 10^{-4}
$$

\subsection{Results report}

When 5 samples are measured each time, and the average value is used to report the result, the expanded uncertainty. $U(X)=6.66 \times 10^{-4} \quad(9)$. Inclusion factor $\mathrm{k}=2$.。

\section{Conclusion}

In this paper, through a specific analysis of the measurement uncertainty in the measurement of ceramic tile wet expansion, the uncertainty of ceramic tile wet expansion is finally obtained. In the test process, there are many factors that affect the final test results. Only by scientifically and rationally analyzing the factors caused by the uncertainty, reasonably evaluating the uncertainty, and taking the influence of the uncertainty into account in the test process, can the ceramic tile wet expansion Obtain accurate test data during the test.

\section{References}

1. Li Lingmei, Zhang Xin, Hu Jianhua, et al. Evaluation of measurement uncertainty with wooden straight (folding) ruler[J]. Foreign Electronic Measurement Technology, 2015, 34(4): 36-38.
2. Ling Mingyang, Li Huimin, Li Jiansheng, et al. Quasi Monte Carlo evaluation method of measurement uncertainty with correlation $[\mathrm{J}]$. Chinese Journal of Scientific Instrument, 2014, 5-13.

3.Ye Depei, Zhao Feng, Shi Changyan, etc., Measurement Uncertainty Evaluation and Table [5]. Beijing: China Metrology Press, 2012. 